Check for updates

Cite this: RSC Adv., 2018, 8, 41299

Received 24th October 2018 Accepted 3rd December 2018

DOI: $10.1039 / \mathrm{c} 8 \mathrm{ra} 08816 \mathrm{k}$

rsc.li/rsc-advances

\section{Si nanocrystal solution with stability for one yeari}

\author{
Daisuke Kajiya $^{\text {ab }}$ and Ken-ichi Saitow (D) *ab
}

Colloidal silicon nanocrystals (SiNCs) are a promising material for next-generation nanostructured devices. High-stability SiNC solutions are required for practical use as well as studies on the properties of SiNC. Here, we show a solution of SiNCs that was stable for one year without aggregation. The stable solution was synthesized by a facile process, i.e., pulsed laser ablation of a Si wafer in isopropyl alcohol (IPA). The long-term stability was due to a large $\zeta$-potential of $-50 \mathrm{mV}$ from a SiNC passivation layer composed of oxygen, hydrogen, and alkane groups, according to the results of eight experiments and theoretical calculations. This passivation layer also resulted in good performance as an additive for a conductive polymer film. Namely, a 5-fold enhancement in carrier density was established by the addition of SiNCs into an organic conductive polymer, poly(3-dodecylthiophene), which is useful for solar cells. Furthermore, it was found that fresh ( $<1$ day) and aged ( 4 months) SiNCs give the same enhancement. The long-term stability was attributed to a great repulsive energy in IPA, whose value was quantified as a function the distance between SiNCs.

\section{Introduction}

Colloidal semiconductor nanoparticles (NPs) have attracted great interest in the field of electronic, photonic, and magnetic materials. ${ }^{1-3}$ Specifically, colloidal NPs, e.g., those used in printed electronics, are a promising material for development of quantum dot displays, sensors, solar cells, and flexible circuits via solution processes. ${ }^{4-6}$ One problem that must be solved is creation of stable colloidal NPs that do not aggregate during production processing and storage. ${ }^{7-9}$ To solve this problem, NPs have been stabilized by surface modification for steric hindrance ${ }^{\mathbf{1 0 - 1 3}}$ or electrostatic interaction..$^{\mathbf{1 0}-16}$ In fact, NPs with surface passivation appear as an optically clear solution for up to several months, whereas NPs without passivation form a cloudy dispersion in a short time..$^{17-19}$

Synthesis of surface-passivated NPs is principally categorized into chemical ${ }^{8,13,20}$ and physical ${ }^{14,21,22}$ methods. In chemical methods, reduction and decomposition of reactants synthesizes colloidal NPs with a stability of up to months, e.g., no aggregation of Au NPs for eleven months via passivation with longchain polyethylene glycol groups ${ }^{20}$ and of ZnO NPs for six months via passivation with the long-chain functional group methacrylate. ${ }^{18}$ Physical synthesis methods such as milling, plasma treatment, sputtering, etching, and sonication of target

${ }^{a}$ Natural Science Center for Basic Research and Development (N-BARD), Hiroshima University, 1-3-1 Kagamiyama, Higashi-hiroshima, Hiroshima 739-8526, Japan. E-mail: saitow@hiroshima-u.ac.jp

${ }^{b}$ Department of Chemistry, Graduate School of Science, Hiroshima University, 1-3-1 Kagamiyama, Higashi-hiroshima, Hiroshima 739-8526, Japan

$\dagger$ Electronic supplementary information (ESI) available. See DOI: 10.1039/c8ra08816k materials produce concentrated solutions of NPs with no precipitation and stable optical properties that last for months. ${ }^{22}$ However, almost all methods require various reagents, multiple steps, high temperatures, vacuum conditions, and long synthesis times. Another critical issue is that the NP surfaces are sensitive to carrier injection and transport in a device. ${ }^{16}$ Specifically, long-chain passivation disturbs carrier injection and transport in the device, whereas short-chain passivation causes aggregation of NPs. Accordingly, a trade-off exists between long-term stability and good performance of electrical materials.

Another good synthesis method for NPs known as pulsed laser ablation ${ }^{23-58}$ in liquid (PLAL) is a promising approach used to obtain stable colloidal NPs, as shown in Scheme 1. This method consists of a one-step process conducted at room temperature with a short duration, e.g., a few minutes to an hour. ${ }^{24,43,56}$ In addition, the scalability of NPs in PLAL has attracted much attention, e.g., a synthesis rate as high $4 \mathrm{~g} \mathrm{~h}^{-1} .^{58}$ To this end, production of Si nanocrystals (SiNCs) by PLAL has been investigated in various liquids (Table S1, ESI $\dagger$ ), and a clear colour and stability for a period of at least forty days were observed in alcohol. ${ }^{34,39,54}$ Therefore, passivated SiNCs have been synthesized by PLAL in alkyl, halide, and aromatic

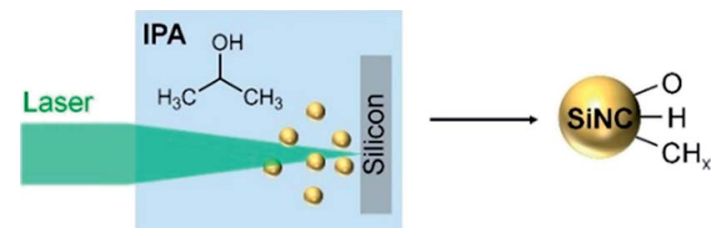

Scheme 1 Illustration of PLAL to generate SiNCs. 
hydrocarbons, ${ }^{\mathbf{4 0 , 5 2}}$ and stable optical properties over a period of months were observed after long-alkyl passivation. ${ }^{33,44}$ Because $\mathrm{Si}$ is a bioinert, abundant, and cost-effective material, ${ }^{59-62}$ colloidal SiNPs have been used to develop solar cells, ${ }^{63}$ light emitters, ${ }^{64}$ on-skin sensors, ${ }^{65}$ and Li-ion batteries ${ }^{66}$ via solution processes. ${ }^{67-76}$

In a previous study, we synthesized SiNCs using the two different methods of PLA ${ }^{30,35,42,44,46,47,54}$ and ball milling, ${ }^{77}$ both of which are mechano-synthesis methods. We note that the SiNCs prepared by ball milling in isopropyl alcohol (IPA) showed notably long-term (4 months) stability, which is attributed to their large $\zeta$-potential. ${ }^{77}$ However, the essential factor in achievement of long-term stability and the mechanism of the large $\zeta$-potential has not yet been understand. Because ball milling itself is a simple method, this approach involves complex processes that require understanding of the details of the reaction mechanism. Interestingly, laser light is a welldefined source of measurable energy injected into a material during synthesis, and theoretical research on nanoparticle synthesis has been reported in PLAL.

In this work, we describe a SiNCs solution synthesized by PLAL in IPA that is stable for one year (Scheme 1). The particle sizes and $\zeta$-potential were tracked for one year. In addition, the structures and optical properties of the SiNCs were quantified using eight experimental methods and theoretical calculations. Furthermore, it was found that the stable SiNCs solution demonstrate 5 -fold enhancement of charge density when involved in a flexible film prepared by a wet process.

\section{Experimental}

PLAL was conducted using the second harmonic of a Nd:YAG laser (Rayture Systems, $\mathrm{RH}-30$ ) as a light source for $1 \mathrm{~h}$ at a repetition rate of $20 \mathrm{~Hz}$. The laser was operated at $532 \mathrm{~nm}$ with a pulse width of $7 \mathrm{~ns}$. The laser fluence during PLAL was in the range from 0.2 to $0.9 \mathrm{~J} \mathrm{~cm}^{-2}$, which were adjusted by changing the irradiated area. Namely, diameters of these area were set as $1.1,1.9$, and $1.5 \mathrm{~mm}$ for fluences of $0.2,0.5$, and $0.9 \mathrm{~J} \mathrm{~cm}^{-2}$, respectively, on the surface of a target Si wafer. A crystal Si wafer with a (111) plane (500441 or 500439, Nilaco) was immersed in IPA (29113-95, NACALAI TESQUE) with a volume of $1.5 \mathrm{~mL}$ in a quartz cuvette at room temperature. After PLAL, the SiNC solutions were filtered using a PTFE syringe filter with a pore size of $0.2 \mu \mathrm{m}$ (6784-1302, Whatman).

Dynamic light scattering (DLS) measurements were performed using a commercial instrument (Zetasizer Nano ZS, Malvern Instruments) with a wavelength of $532 \mathrm{~nm}$ to determine the size distribution and $\zeta$-potential of the SiNCs dispersed in IPA. The sizes of the dried SiNCs were analyzed using transmission electron microscopy (TEM) (JEM-2011, JEOL). The TEM samples were prepared by dropping the SiNC solution onto TEM grids (10-1013, STEM Cu100P, Okenshoji Co., Ltd.) in a glovebox (UNILab, MBRAUN) filled with highpurity argon gas (99.999\%, Taiyo Nippon Sanso). The Raman spectra of the dried SiNCs were measured using a commercial Raman spectrometer (T64000, Horiba Jobin Yvon) at an excitation wavelength of $514.5 \mathrm{~nm}$. The Fourier transform infrared
(FTIR) (FT/IR-4200, Jasco) spectra of the SiNCs were measured by the attenuated total reflectance (ATR) method for droplets of the sample (SiNCs in IPA) and reference (IPA) on an ATR prism made of zinc selenide (ATR PRO450-S, Jasco). X-ray photoelectron spectroscopy (XPS) was performed using a spectrometer (ESCA3400, Shimadzu) with $\mathrm{Mg} \mathrm{K}_{\alpha}$ as the X-ray source.

The SiNC/poly(3-dodecylthiophene) (P3DDT) hybrid film was prepared by the successive drop-casting method described elsewhere. ${ }^{47}$ Briefly, SiNCs dissolved in 2-propanol were dropped onto an indium tin oxide (ITO)-coated glass substrate (FLAT-ITO, Geomatec), followed by drop casting of P3DDT (regioregularity 97\%, $M_{\mathrm{w}}=27 \mathrm{kDa}, \mathrm{PDI}=1.5$, Sigma Aldrich) dissolved in chlorobenzene onto the SiNCs. The weight ratio in the hybrid film was $25 \mathrm{wt} \%$ SiNCs and $75 \mathrm{wt} \%$ P3DDT, which was determined using an analytical balance (Sartorius, MC1). After the film was dried for $12 \mathrm{~h}$ in air at room temperature, an Al electrode was deposited on the film using a vacuum evaporation system (SVC-700TM, Sanyu Electron). A pristine P3DDT film was prepared in the same manner as the hybrid film without SiNCs. The photoconductivity of films with thicknesses of 4-5 $\mu \mathrm{m}$ was measured using an in-house-built instrument described elsewhere. ${ }^{78}$ The light source was the second harmonic of an Nd:YAG laser $(\lambda=532 \mathrm{~nm}, 7 \mathrm{~ns}, 6 \mathrm{~Hz}, 0.5 \mu \mathrm{J}$ per pulse). The photoluminescence (PL) decay of the films was measured using a photon counting method (Fluorocube, Horiba) at an excitation wavelength of $453 \mathrm{~nm}$ and a luminescence wavelength of $720 \mathrm{~nm}$. The surface roughnesses of the films were measured using a confocal laser microscope (Shimadzu, OLS4000) equipped with a $100 \times$ objective and an atomic force microscope (SPM-9700, Shimadzu) in tapping mode.

\section{Results and discussion}

Fig. 1a shows the transmission electron microscopy (TEM) images of the products synthesized by PLAL in IPA. The mean sizes of the products were 12, 8 , and $6 \mathrm{~nm}$ at laser fluences of $0.2,0.5$, and $0.9 \mathrm{~J} \mathrm{~cm}^{-2}$, respectively. The lattice fringe of the (111) plane of crystalline Si was observed in all images. Thus, the products are crystalline Si nanoparticles. Fig. 1b shows the Raman spectra of the products. The crystalline-Si band at $520 \mathrm{~cm}^{-1}$ is present, but the amorphous-Si band at $480 \mathrm{~cm}^{-1}$ is absent. These results indicate that the product is composed of SiNC. The size of the crystalline region involved in the SiNC was estimated using an empirical equation relating Raman shift $(\nu)$ and crystalline size $(D)$ of spherical SiNC (Fig. S1†): ${ }^{79-81}$

$$
\nu=\nu_{0}-47.41(0.543 / D)^{1.44}
$$

where $\nu_{0}$ is the Raman shift of bulk-crystal Si. As a result, the crystalline sizes were 12,6 , and $5 \mathrm{~nm}$ for $0.2,0.5$, and $0.9 \mathrm{~J} \mathrm{~cm}^{-2}$, respectively, as listed in Table 1.

Fig. 1c shows a typical result for DLS of SiNCs dispersed in IPA. The single size distribution reveals a good dispersion of colloidal SiNCs. As shown in Fig. 1d, the mean sizes of the SiNCs were 13, 8, and $6 \mathrm{~nm}$ as number-weighted size and 16, 10, and $7 \mathrm{~nm}$ as volume-weighted size for $0.2,0.5$, and $0.9 \mathrm{~J} \mathrm{~cm}^{-2}$, 
a
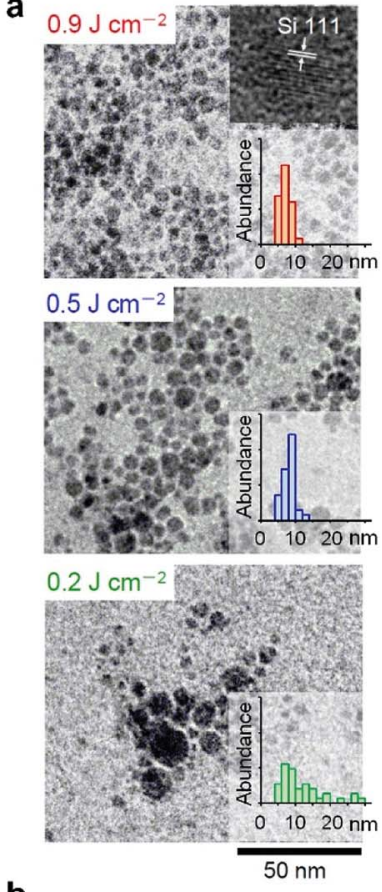

b

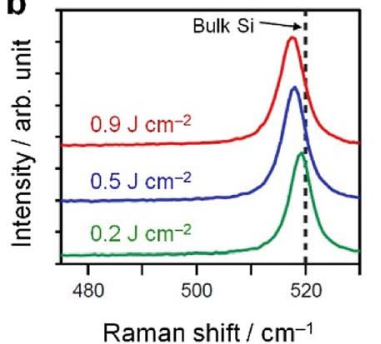

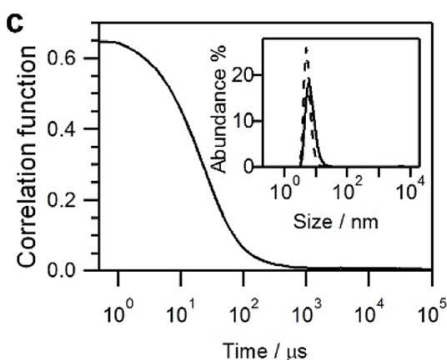

d

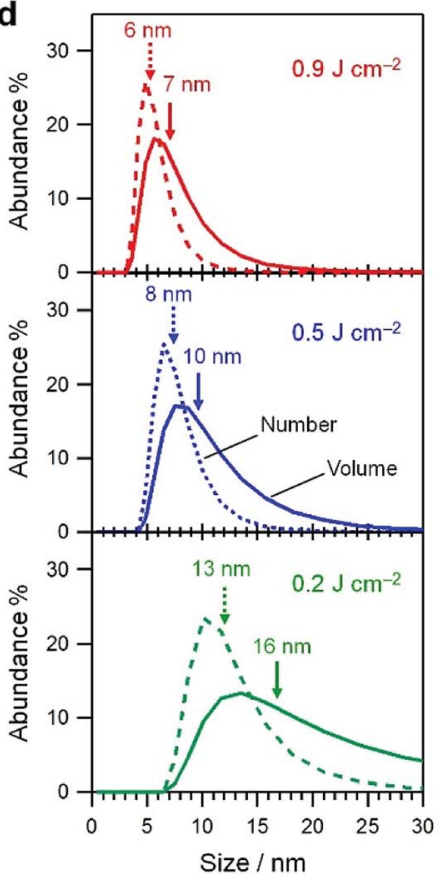

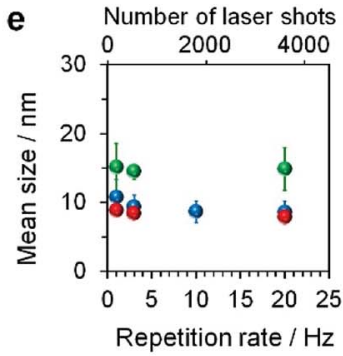
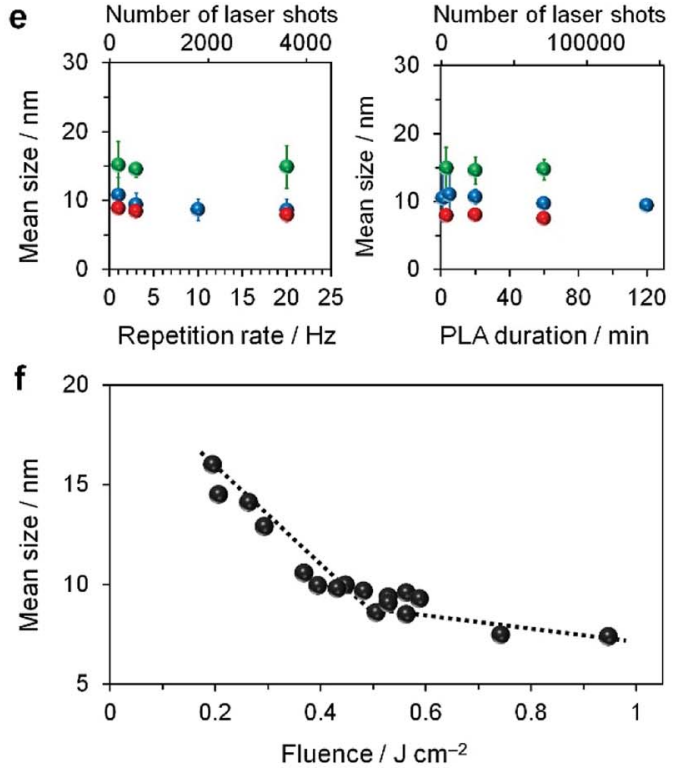

g

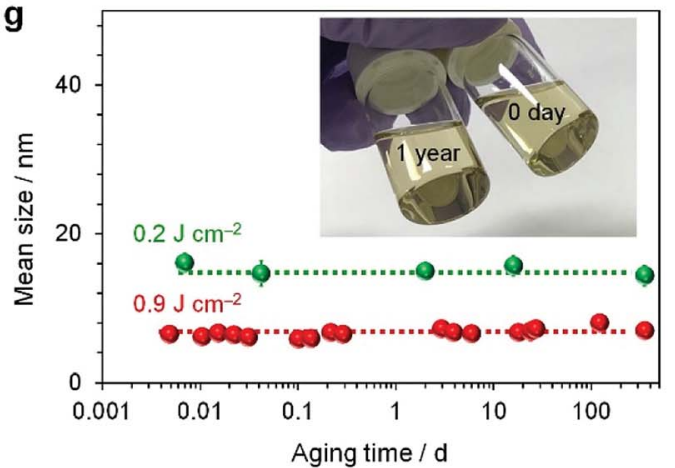

Fig. 1 (a) TEM, (b) Raman, and (c)-(g) DLS results. (a) and (b) TEM images and Raman spectra of SiNCs synthesized by PLAL at fluences of 0.9, 0.5, or $0.2 \mathrm{~J} \mathrm{~cm}^{-2}$. Histogram is obtained from thirty SiNCs. The dashed line is the frequency of the Raman band for bulk-crystal Si. (c) A typical DLS result for the time correlation function of SiNCs dispersed in IPA. The inset shows the size distribution of SiNCs determined by analyzing the correlation function using the nonnegative least-squares method. The size distributions weighted by volume and number are shown by solid and dashed curves, respectively. (d) Fluence dependence of the size distribution of the SiNCs. Arrows denote the mean size. The volume-weighted mean size of SiNCs in IPA as a function of: (e) PLAL repetition rate and duration, (f) laser fluence, and (g) aging time. Dotted lines are used as a visual guide. The photograph in ( $g$ ) shows the SiNCs in IPA before and after aging for one year.

respectively (Table 1). Their mean sizes and size-distribution profiles are similar to those observed in the TEM images (Fig. 1a). Note that the size was independent of the PLAL parameters, such as the repetition rate $(1-20 \mathrm{~Hz})$ and duration (1-120 min), as shown in Fig. 1e. However, the size was tunable continuously by the laser fluence, as shown in Fig. 1f. Additionally, the size did not change during aging in IPA for one year
(Fig. 1g). The photograph in Fig. 1g shows the solutions of SiNCs dispersed in IPA before and after aging, which are similar to each other. Therefore, a stable colloid SiNC is synthesized by a nanosecond laser pulse on a Si wafer immersed in IPA.

Fig. 2a shows the $\zeta$-potentials of SiNCs dispersed in IPA. Their values are listed in Table 1. A large negative value of $-50 \mathrm{mV}$ is observed and remains for one year. This result is the

Table 1 The mean size, $\zeta$-potential, and passivation ratio of SiNCs synthesized at different fluences. The analysis of the passivation ratio in described in Note S1 of the ESI

\begin{tabular}{|c|c|c|c|c|c|c|c|c|}
\hline \multirow{2}{*}{ Fluence $\left(\mathrm{J} \mathrm{cm}^{-2}\right)$} & \multicolumn{4}{|c|}{ Mean size (nm) } & \multirow{2}{*}{$\zeta$-Potential (mV) } & \multicolumn{3}{|c|}{ Passivation ratio (\%) } \\
\hline & TEM & Raman & \multicolumn{2}{|l|}{ DLS } & & $\mathrm{Si}-\mathrm{O}$ & $\mathrm{Si}-\mathrm{H}$ & $\mathrm{Si}-\mathrm{CH}_{x}$ \\
\hline 0.2 & $12.1 \pm 2.8$ & $11.9 \pm 0.9$ & $13.0 \pm 1.6$ & $15.8 \pm 1.6$ & -54 & 37 & 34 & 29 \\
\hline 0.5 & $8.0 \pm 0.6$ & $5.8 \pm 0.5$ & $8.2 \pm 0.5$ & $9.7 \pm 1.6$ & -46 & 35 & 33 & 32 \\
\hline
\end{tabular}


same as the previous result obtained for SiNCs prepared by ball milling in IPA. ${ }^{77}$ Such a large $\zeta$-potential is considered a driving force for a good dispersion of colloidal SiNCs without aggregation (vide infra).

To investigate the origin of the large negative $\zeta$-potential, we measured the Fourier transform infrared (FTIR) spectra of SiNCs (Fig. 2b) and analysed the number of functional groups using their oscillator strengths. ${ }^{\mathbf{8 2 , 8 3}}$ The spectra indicate the $\mathrm{Si}-$ $\mathrm{O}, \mathrm{Si}-\mathrm{H}, \mathrm{Si}-\mathrm{C}$, and $\mathrm{C}-\mathrm{H}$ stretching modes of the functional
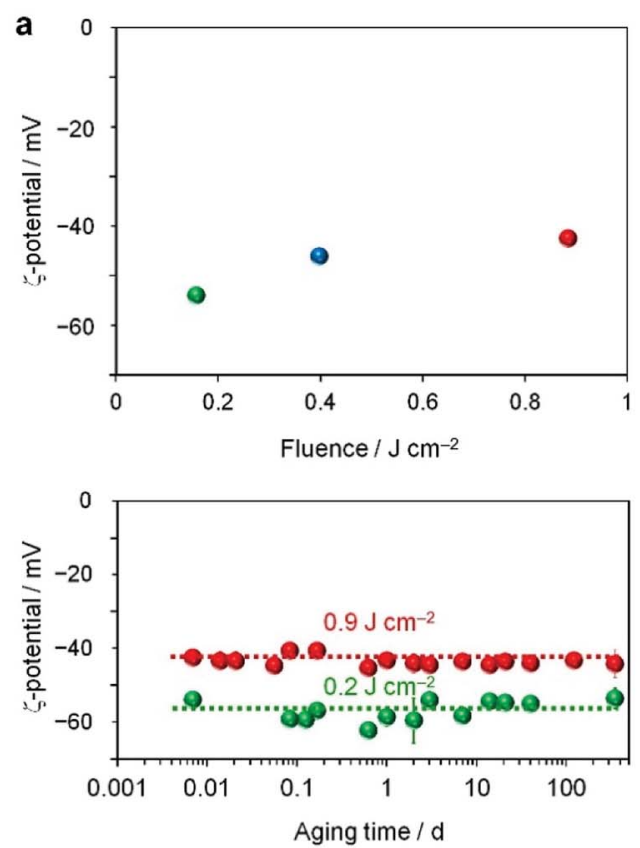

b

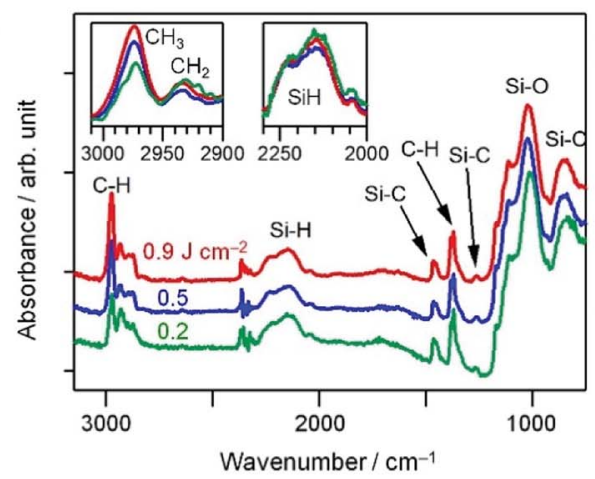

C

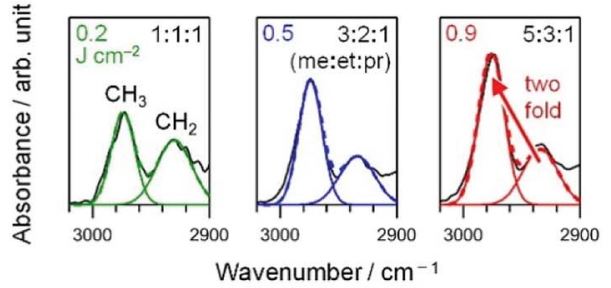

Fig. 2 (a) The $\zeta$-potential of SiNCs in IPA (top) and its aging-time dependence (bottom). Dotted lines are used as visual guides. (b) FTIR spectra of SiNCs. Insets show data for the $\mathrm{C}-\mathrm{H}$ or $\mathrm{Si}-\mathrm{H}$ stretching mode regions. (c) The analysis of the $\mathrm{C}-\mathrm{H}$ stretching mode for $\mathrm{CH}_{3}$ and $\mathrm{CH}_{2}$ components using the Gaussian functions. The ratios denote the number ratio of methyl, ethyl, and propyl groups considered as passivation species of short alkyl chains. groups attached to the SiNCs as the passivation species of $\mathrm{O}, \mathrm{H}$, and $\mathrm{CH}_{x}$. The $\mathrm{CH}_{x}$ species are assigned to short alkyl chains such as either methyl, ethyl, or propyl groups. This is because the integrated intensity of spectrum for $\mathrm{CH}_{3}\left(\approx 2970 \mathrm{~cm}^{-1}\right)^{22,82}$ is higher than that of $\mathrm{CH}_{2}\left(\approx 2930 \mathrm{~cm}^{-1}\right) \cdot{ }^{22,82}$ Namely, the intensity is two-fold high, as shown in Fig. 2c. The two-fold is given by the combination of methyl, ethyl, propyl groups, whose ratios are $5: 3: 1$, respectively. Table 1 lists the relative amounts of the functional groups; the $\mathrm{Si}-\mathrm{O}, \mathrm{Si}-\mathrm{H}$, and $\mathrm{Si}-\mathrm{CH}_{x}$ components comprise 37,34 , and $29 \%$, respectively, for $0.2 \mathrm{~J} \mathrm{~cm}^{-2}$ (Note $\mathrm{S} 1 \dagger$ ). $\mathrm{Si}-\mathrm{O}$ and $\mathrm{Si}-\mathrm{H}$ have a negative charge, whereas $\mathrm{Si}-$ $\mathrm{CH}_{x}$ has a positive charge. The net charge becomes negative, as described in Note $\mathrm{S} 2 . \dagger$ The SiNCs repel each other and do not agglomerate due to the negative charge. In fact, no aggregation is observed with a negative $\zeta$-potential, as shown in Fig. $1 \mathrm{~g}$ and 2a. Table 1 also shows that the passivation ratio is changed by the laser fluence. A higher fluence results in more $\mathrm{Si}-\mathrm{CH}_{x}$. Namely, the negativity of the $\zeta$-potential decreases with the increasing fluence. In fact, such a trend is observed in the $\zeta$ potential, as shown in Fig. 2a.

Chemical species on the surface of SiNPs were also analysed by XPS measurements. C, O, Si, and $\mathrm{Al}$ elements are observed using SiNCs deposited on an $\mathrm{Al}$ substrate, as shown in Fig. 3a. The former three elements are due to SiNCs and the latter one is the substrate. Fig. 3b shows $\mathrm{Si}-\mathrm{O}, \mathrm{Si}-\mathrm{H}, \mathrm{Si}-\mathrm{C}$, and $\mathrm{C}-\mathrm{H}$ bands. Since the species are in good agreement with the results of FTIR spectra, it can be concluded that the SiNCs prepared by PLAL in IPA are passivated by the functional groups.

To discuss the synthesis mechanism that depends on the laser fluence, we estimated the temperature increase due to
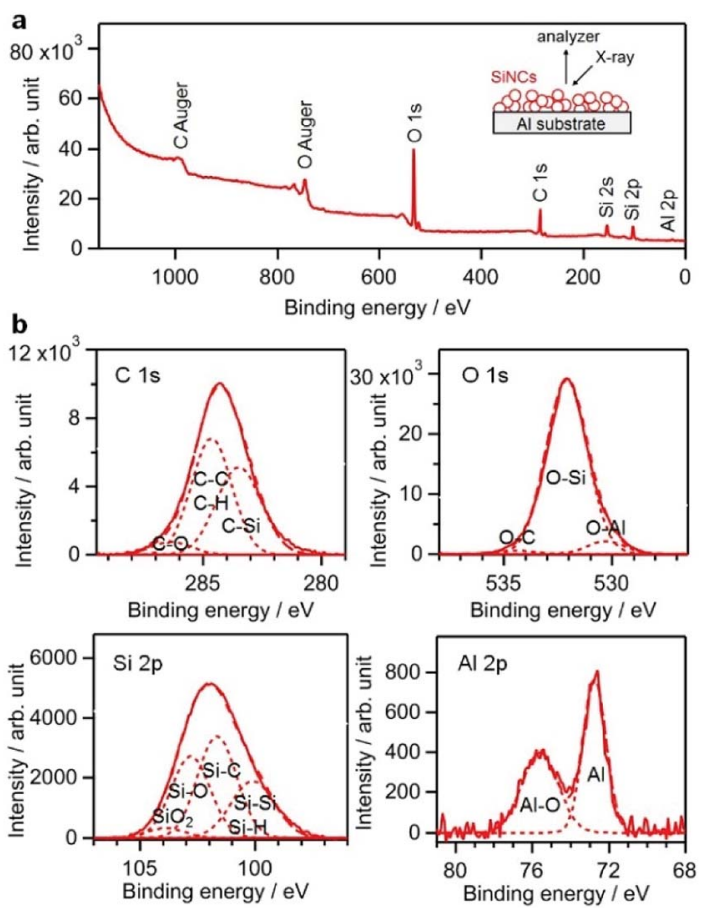

Fig. 3 XPS spectra of SiNCs. (a) Survey spectrum. (b) Spectra for $C 1 \mathrm{~s}$, $\mathrm{O} 1 \mathrm{~s}$, Si $2 \mathrm{p}$, and Al 2p. The spectra were analysed using the Gaussian functions. 
laser irradiation of a single shot on the Si target. The calculation was conducted using a heat conduction equation for PLA. ${ }^{\mathbf{8 4 , 8 5}}$

$$
\begin{gathered}
\frac{\partial T(x, t)}{\partial t}=\frac{\partial}{\partial x}\left(D_{\mathrm{T}} \frac{\partial T(x, t)}{\partial x}\right)+\frac{E(x, t)}{\rho C_{\mathrm{P}}} \\
T(x, t)=(1-R) \lambda^{-1}\left(\frac{D_{\mathrm{T}}}{\pi}\right)^{1 / 2} \int_{0}^{t} I(t-\tau) \exp \left(-\frac{x^{2}}{4 D_{\mathrm{T}} \tau}\right) \tau^{-1 / 2} \mathrm{~d} \tau
\end{gathered}
$$

where $T$ is the temperature; $t$ is the time; $x$ is the position $(x=$ 0 at surface); $D_{\mathrm{T}}, \rho, C_{\mathrm{P}}, R$, and $\lambda$ are the thermal diffusivity, density, heat capacity, reflectivity, and thermal conductivity, respectively, of the Si target; $E$ is the energy from the laser; and $I$ is the incident power density of the spatially uniform laser. Fig. 4 shows the calculated results of the temperature over time before and after pulse laser irradiation. When the fluence is low $\left(0.2 \mathrm{~J} \mathrm{~cm}^{-2}\right)$, the temperature increases to the melting point of $\mathrm{Si}^{86}$ Since SiNCs at $0.2 \mathrm{~J} \mathrm{~cm}^{-2}$ are large and inhomogeneous (Fig. 1a), the results indicate that large and inhomogeneous SiNCs are generated near the threshold of melting. When the fluence is high $\left(0.9 \mathrm{~J} \mathrm{~cm}^{-2}\right)$, the temperature is high (Fig. 4), and the size is small (Fig. 1f). Thus, a higher temperature produces smaller SiNCs. It has been reported that higher temperatures cause smaller critical-size nuclei, which share ablated Si and become smaller SiNCs. ${ }^{34,87}$ Thus, a higher fluence results in smaller SiNCs.

Next, we investigated the fluence dependence of passivation. According to a previous $a b$ initio calculation for the thermal decomposition of IPA $^{\mathbf{8 8}}$ the following reaction occurs as a principle pathway at a temperature higher than $1200 \mathrm{~K}$

$$
\mathrm{CH}_{3} \mathrm{C}(\mathrm{H}) \mathrm{OHCH}_{3} \rightarrow \mathrm{CH}_{3} \mathrm{C}(\mathrm{H}) \mathrm{OH}+\mathrm{CH}_{3}
$$
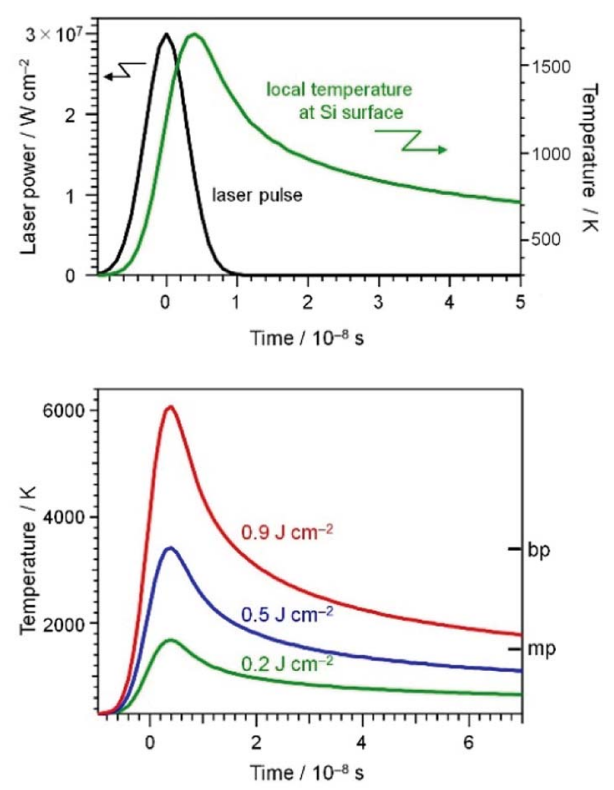

Fig. 4 A time profile of the calculated temperature on the Si-target surface by laser pulse irradiation (top) and its fluence dependence (bottom). The $\mathrm{mp}$ and bp denote the melting point and boiling point, respectively, of bulk-crystal $\mathrm{Si}^{86}$
The calculated temperature was higher than $1200 \mathrm{~K}$ from a few nanoseconds to a few tens of nanoseconds, as shown in Fig. 4. The reaction (4) produces alkyl species, which can attach to SiNCs as alkyl passivation. This reaction (4) becomes more dominant than other decomposition reactions as the temperature increases. ${ }^{\mathbf{8}}$ Since a higher fluence causes a higher temperature, as shown in Fig. 4, more alkyl passivation can appear at a higher fluence. In fact, an increase in alkyl passivation with an increase in fluence is observed in the FTIR results, as shown in Table 1. A higher ratio of alkyl passivation is obtained with a higher fluence. The positive charge of the alkyl group reduces the negative $\zeta$-potential, and the negative $\zeta$ potential decreases as the fluence increases, as shown in Fig. 2a.

A solution-processed SiNCs/P3DDT hybrid film was demonstrated as an example of printed solar cell application. The P3DDT is a conductive polymer with good flexibility, photostability, and mechanical durability. ${ }^{89,90}$ Fig. 5a shows the time profile of photogenerated holes in a P3DDT pristine film or a SiNC/P3DDT hybrid film. The SiNCs were used within one day or four months of synthesis at $0.9 \mathrm{~J} \mathrm{~cm}^{-2}$. The integratedintensity profile for the hybrid film is higher than that for the pristine film. This result indicates a higher hole density in the hybrid film. The magnitude of the hole density was estimated using a previous method. ${ }^{47}$ As a result, a 5-fold enhancement was evaluated by the addition of SiNCs into a P3DDT film, as shown in Fig. 5b (photo-conversion efficiency was estimated in Note $\mathrm{S} 3 \dagger$ ). Furthermore, the degree of the enhancement is the same for fresh and aged SiNCs. Hole densities of the hybrid films composed of SiNC (fresh $<1$ day)/P3DDT and SiNC (aged 4 months $) /$ P3DDT were $(5.0 \pm 0.3) \times 10^{-9}$ and $(4.7 \pm 0.6) \times 10^{-9}$ $\mathrm{C}$, respectively (Fig. 5b). Here, let us mention the reason for the enhancement. It can be attributed to the charge separation of P3DDT excitons (Fig. S2 $\dagger$ ), because an electron can transfer from P3DDT to the SiNCs at the P3DDT/SiNCs interface, according to the energy diagram in Fig. 5c. In addition, alkyl passivation allows energy transfer with no energy barrier, ${ }^{47,91-93}$ as shown in Fig. 5c. This explanation is consistent with the results of PL decay. PL decay of the hybrid film is faster than that of the pristine film due to faster charge separation, as shown in Fig. 5d. The hybrid film presented here has a free standing (Fig. 5e) and smooth surface (Fig. 5f and g), which is convenient for integration into soft electronics. Since the light emission of the SiNCs was weak (Fig. S3†), we show not photoemitting but photo-detecting application.

Finally, we describe the details about stability in the current system. The SiNCs in IPA showed large $\zeta$-potential (vide supra). This large $\zeta$-potential is due to a large surface charge, which can cause great repulsive energy between SiNCs by Coulomb's potential, i.e. $V=q^{2} / 4 \pi \varepsilon_{\mathrm{r}} \varepsilon_{0} r$, where $q$ is charge, $\varepsilon_{\mathrm{r}}$ is relative permittivity of solvent, $\varepsilon_{0}$ is the vacuum permittivity, and $r$ is separation of SiNCs. In general, a great repulsive energy results in a good dispersion and a high stability in solution. In addition, the repulsive energy becomes further higher when $1 / \varepsilon_{\mathrm{r}}$ of solvent is large. In fact, the $1 / \varepsilon_{\mathrm{r}}$ of IPA is $0.05,{ }^{86}$ which is larger than that of ethanol $(0.04)$, methanol $(0.03)$, or water $(0.01) .{ }^{86}$ Consequently, IPA solvent used in the present study can give both large repulsive energy and high stability. To understand 


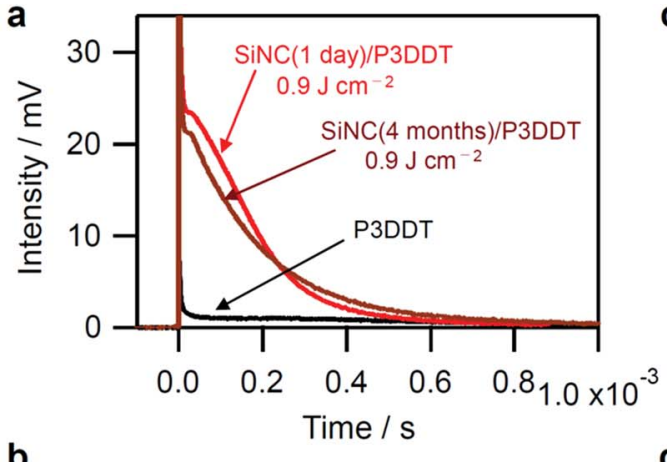

b

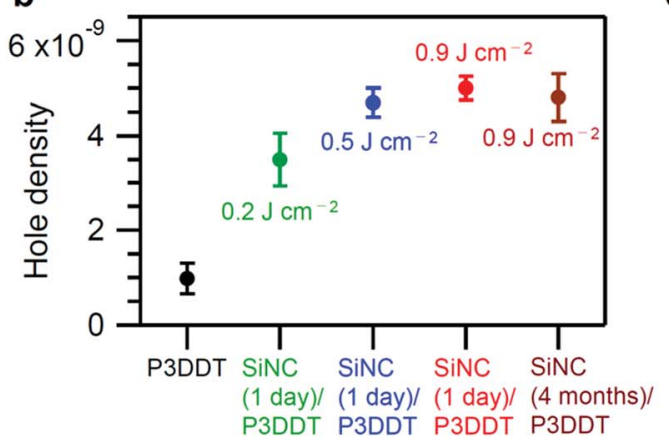

C

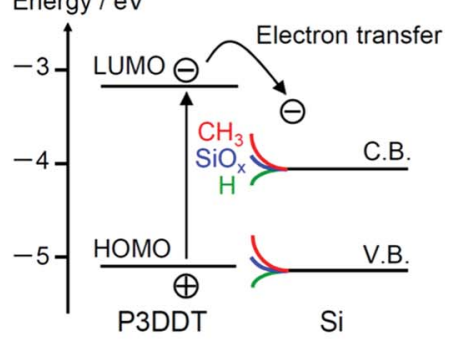

e
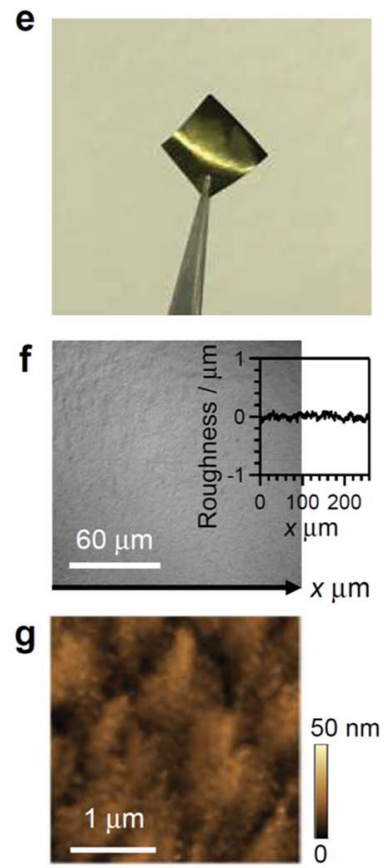

Fig. 5 (a) Time profiles for holes photogenerated in a P3DDT pristine film and a SiNCs/P3DDT hybrid film. The SiNCs were used within 1 day or after 4 months aging in IPA. (b) Hole densities of the pristine and hybrid films. A higher fluence corresponds to a higher alkyl passivation of SiNCs, as listed in Table 1. The SiNCs were used within 1 day or after 4 months. (c) Schematic illustration of the dissociation of P3DDT excitons on the basis of the band diagram of P3DDT and Si. ${ }^{91,92}$ C.B. and V.B. denote conduction and valence bands, respectively, and their energies are changed by the passivation species. The LUMO level of P3DDT lies above the conduction band of Si, which enables exciton dissociation and electron transfer. (d) PL decay for the pristine and hybrid films. (e) A photograph of a free-standing flexible hybrid film, which was obtained by peeling the hybrid film from a substrate using tweezers. (f) The laser microscopy image and surface roughness of the hybrid film. The surface roughnesses of the arithmetic mean height, $S_{a}$, for the hybrid and pristine films were 0.04 and $0.02 \mu \mathrm{m}$, respectively. (g) The atomic force microscope (AFM) height image of the hybrid film.

further detail mechanism, we quantified the repulsive and attractive energies as a function of the distance between SiNCs, based on DLVO (Derjaguin-Landau-Verwey-Overbeek) theory. ${ }^{94}$
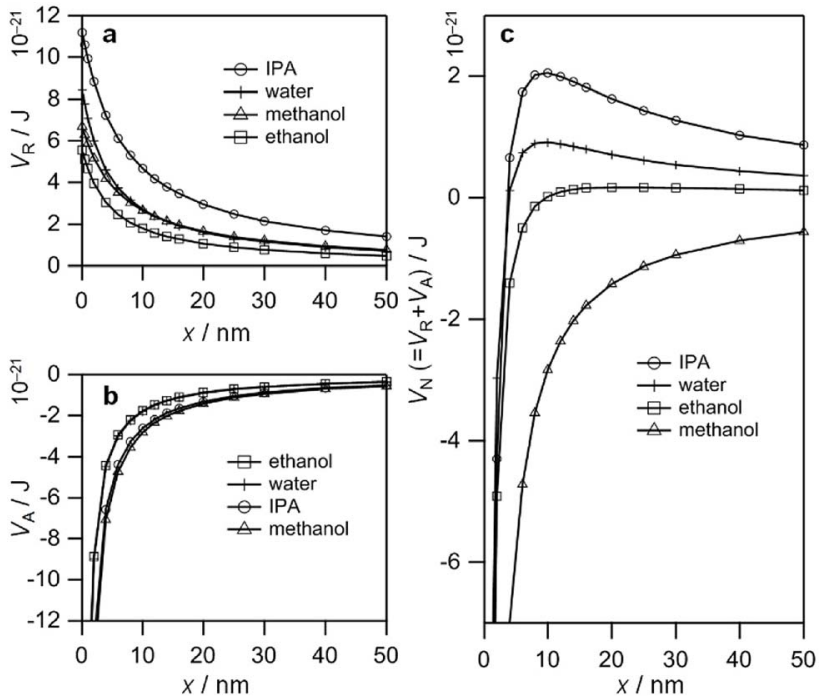

Fig. 6 Calculated results of (a) $V_{R}$ (b) $V_{A}$, and (c) $V_{N}$ between SiNCs in IPA, ethanol, methanol, or water. These data quantify repulsive $\left(V_{R}\right)$ and attractive $\left(V_{A}\right)$ energies between SiNCs in the four solvents as function of the distance.
The calculated results are shown in Fig. 6 using the following equations.

$$
\begin{gathered}
V_{\mathrm{N}}=V_{\mathrm{A}}+V_{\mathrm{R}} \\
V_{\mathrm{A}}=-A a / 12 x \\
V_{\mathrm{R}}=4 \pi \varepsilon_{\mathrm{r}} \varepsilon_{0} a^{2} \zeta^{2} \exp (-\kappa x) /(2 a+x)
\end{gathered}
$$

where $V_{\mathrm{R}}$ and $V_{\mathrm{A}}$ are repulsive and attractive energies, respectively, $A$ the Hamaker constant; ${ }^{95-98} a$ the SiNCs radius; ${ }^{31,54} x$ the distance between two SiNCs surfaces; $\zeta$ the $\zeta$-potential; $\exp (-\kappa x)$ approximately unity at no electrolyte. ${ }^{94}$ According to the results in Fig. 6, the repulsive energy for SiNCs in IPA is the highest in the solvents at the all the distance. Thus, the SiNCs in IPA do not aggregate such as a long period for 1 year. This high stability and quantified analysis of SiNCs are very important for applications, e.g. printed electronics and materials of a Li-ion battery, as well as the interpretation of long stability of SiNCs (4 months), previously synthesized by the ball milling in IPA. ${ }^{77}$

\section{Conclusions}

Colloidal SiNCs were prepared by a one-step and one-pot PLAL method with a Si wafer immersed in IPA in a cuvette. The products were analyzed by DLS, TEM, Raman, $\zeta$-potential, IR, 
XPS, photoconductivity, and PL decay measurements, and temperature and potential-energy calculations. The results show that the SiNCs synthesized were stable for one year in IPA with no aggregation due to a large $\zeta$-potential of $-50 \mathrm{mV}$, which is attributed to a passivation layer composed of oxygen, hydrogen, and short alkyl groups. The mechanism of long-term stability was attributed to the strong repulsive energy among the SiNCs in IPA, whose amounts were calculated as a function of distance of the SiNCs particles in all the solvents. As the other important conclusions, an increase in fluence causes a decrease in the SiNC size and an increase in alkyl passivation due to an increase in temperature. The alkyl passivation contributed to a 5-fold enhancement in the hole density for a solutionprocessed hybrid film, and then this enhancement was not changed using SiNCs aged for 4 months. Such an enhancement can serve for the development of optoelectronics such as solar cells. Thus, stable and applicable SiNCs can be established by a laser and environmentally benign materials. The method presented here does not require toxic reagents, vacuum, and a long time to produce very stable colloidal SiNCs at room temperature and enhances the properties of flexible polymer films.

\section{Conflicts of interest}

There are no conflicts to declare.

\section{Acknowledgements}

The authors acknowledge Mr Kitasako, Dr Maeda, and Dr Dote of Hiroshima University for constructing the PLAL instrument, obtaining the TEM images, and supporting the XPS measurements, respectively. K. S. acknowledges financial support from the Funding Program for the Next-Generation World-Leading Researchers (GR073) of the Japan Society for the Promotion of Science (JSPS), a Grant-in-Aid for Scientific Research (A) (15H02001) from JSPS, and the PRESTO Structure Control and Function Program of the Japan Science and Technology Agency (JST). D. K. acknowledges a Grant-in-Aid for Young Scientists (B) (No. 26790015 and No. 17K14082) from the JSPS.

\section{Notes and references}

1 P. D. Howes, R. Chandrawati and M. M. Stevens, Science, 2014, 346, 1247390.

2 C. R. Kagan, E. Lifshitz, E. H. Sargent and D. V. Talapin, Science, 2016, 353, 885.

3 V. Lesnyak, N. Gaponik and A. Eychmuller, Chem. Soc. Rev., 2013, 42, 2905-2929.

4 (a) Y. Shirasaki, G. J. Supran, M. G. Bawendi and V. Bulović, Nat. Photonics, 2013, 7, 13-23; (b) J. Yang, M. K. Choi, D.-H. Kim and T. Hyeon, Adv. Mater., 2016, 28, 1176-1207.

5 W. U. Huynh, J. J. Dittmer and A. P. Alivisatos, Science, 2002, 295, 2425-2427.

6 (a) G. H. Carey, A. L. Abdelhady, Z. Ning, S. M. Thon, O. M. Bakr and E. H. Sargent, Chem. Rev., 2015, 115, 12732-12763; (b) Z. Yang, J. Z. Fan, A. H. Proppe,
F. P. G. de Arquer, D. Rossouw, O. Voznyy, X. Lan, M. Liu, G. Walters, R. Quintero-Bermudez, B. Sun, S. Hoogland, G. A. Botton, S. O. Kelley and E. H. Sargent, Nat. Commun., 2017, 8, 1325.

7 M. A. El-Sayed, Acc. Chem. Res., 2004, 37, 326-333.

8 (a) M. Dasog, J. Kehrle, B. Rieger and J. G. C. Veinot, Angew. Chem., Int. Ed., 2016, 55, 2322-2339; (b) R. Sinelnikov, M. Dasog, J. Beamish, A. Meldrum and J. G. C. Veinot, ACS Photonics, 2017, 4, 1920-1929; (c) Q. Li, T.-Y. Luo, M. Zhou, H. Abroshan, J. Huang, H. J. Kim, N. L. Rosi, Z. Shao and R. Jin, ACS Nano, 2016, 10, 8385-8393.

9 C. R. Kagan, Chem. Soc. Rev., 2019, DOI: 10.1039/c8cs00629f. 10 D. V. Talapin, J.-S. Lee, M. V. Kovalenko and E. V. Shevchenko, Chem. Rev., 2010, 110, 389-458.

11 R. A. Sperling and W. J. Parak, Philos. Trans. R. Soc., A, 2010, 368, 1333-1383.

12 M. Montalti, A. Cantelli and G. Battistelli, Chem. Soc. Rev., 2015, 44, 4853-4921.

13 (a) J. Zou, R. K. Baldwin, K. A. Pettigrew and S. M. Kauzlarich, Nano Lett., 2004, 4, 1181-1186; (b) J. Zou and S. M. Kauzlarich, J. Cluster Sci., 2008, 19, 341-355; (c) M. Dasog, Z. Yang, S. Regli, T. M. Atkins, A. Faramus, M. P. Singh, E. Muthuswamy, S. M. Kauzlarich, R. D. Tilley and J. G. C. Veinot, ACS Nano, 2013, 7, 2676-2685; (d) S. Bhattacharjee, I. M. C. M. Rietjens, M. P. Singh, T. M. Atkins, T. K. Purkait, Z. Xu, S. Regli, A. Shukaliak, R. J. Clark, B. S. Mitchell, G. M. Alink, A. T. M. Marcelis, M. J. Fink, J. G. C. Veinot, S. M. Kauzlarich and H. Zuilhof, Nanoscale, 2013, 5, 4870-4883.

14 (a) L. Mangolini and U. Kortshagen, Adv. Mater., 2007, 19, 2513-2519; (b) Z. C. Holman and U. R. Kortshagen, Nano Lett., 2011, 11, 2133-2136.

15 (a) M. Sakiyama, H. Sugimoto and M. Fujii, Nanoscale, 2018, 10, 13902-13907; (b) H. Sugimoto, M. Fujii, K. Imakita, S. Hayashi and K. Akamatsu, J. Phys. Chem. C, 2013, 117, 11850-11857; (c) H. Sugimoto, M. Fujii, K. Imakita, S. Hayashi and K. Akamatsu, J. Phys. Chem. C, 2012, 116, 17969-17974; (d) M. Fujii, H. Sugimoto and S. Kano, Chem. Commun., 2018, 54, 4375-4389.

16 (a) S. Zhou, Z. Ni, Y. Ding, M. Sugaya, X. Pi and T. Nozaki, ACS Photonics, 2016, 3, 415-422; (b) İ. Doğan, R. Gresback, T. Nozaki and M. C. M. van de Sanden, Sci. Rep., 2016, 6, 29508.

17 B. F. P. McVey, S. Prabakar, J. J. Gooding and R. D. Tilley, ChemPlusChem, 2017, 82, 60-73.

18 (a) C.-H. Hung and W.-T. Whang, J. Mater. Chem., 2005, 15, 267-274; (b) Y.-S. Lin, N. Abadeer and C. L. Haynes, Chem. Commun., 2011, 47, 532-534; (c) O. S. Muddineti, P. Kumari, S. Ajjarapu, P. M. Lakhani, R. Bahl, B. Ghosh and S. Biswas, Nanotechnology, 2016, 27, 325101; (d) J. L. Weaver, G. A. Tobin, T. Ingle, S. Bancos, D. Stevens, R. Rouse, K. E. Howard, D. Goodwin, A. Knapton, X. Li, K. Shea, S. Stewart, L. Xu, P. L. Goering, Q. Zhang, P. C. Howard, J. Collins, S. Khan, K. Sung and K. M. Tyner, Part. Fibre Toxicol., 2017, 14, 25; (e) D. M. Arboleda, J. M. J. Santillána, V. B. Arcea, M. B. F. van Raap, D. Muraca, M. A. Fernándeze, R. M. T. Sanchez, 
D. C. Schinca and L. B. Scaffardi, Mater. Charact., 2018, 140, 320-332.

19 (a) Y. Yu, C. M. Hessel, T. D. Bogart, M. G. Panthani, M. R. Rasch and B. A. Korgel, Langmuir, 2013, 29, 15331540; (b) D. A. Silbaugh, L. Ferrer-Tasies, J. Faraudo, J. Veciana, N. Ventosa and B. A. Korgel, Langmuir, 2017, 33, 14366-14377.

20 Y. Sun, H. Sai, F. von Stein, M. Riccio and U. Wiesner, Chem. Mater., 2014, 26, 5201-5207.

21 H. Wang, Z. Xu, M. J. Fink, D. Shchukin and B. S. Mitchell, Chem. Commun., 2015, 51, 1465-1468.

22 A. S. Heintz, M. J. Fink and B. S. Mitchell, Adv. Mater., 2007, 19, 3984-3988.

23 (a) F. Mafuné, J. Kohno, Y. Takeda, T. Kondow and H. Sawabe, J. Phys. Chem. B, 2000, 104, 8333-8337; (b) F. Mafuné, J. Kohno, Y. Takeda, T. Kondow and H. Sawabe, J. Phys. Chem. B, 2000, 104, 9111-9117.

24 (a) V. Amendola and M. Meneghetti, Phys. Chem. Chem. Phys., 2009, 11, 3805-3821; (b) V. Amendola and M. Meneghetti, Phys. Chem. Chem. Phys., 2013, 15, 30273046.

25 H. Kurita, A. Takami and S. Koda, Appl. Phys. Lett., 1998, 72, 789-791.

26 I. Umezu, K. Shibata, S. Yamaguchi and A. Sugimura, J. Appl. Phys., 1998, 84, 6448-6450.

27 Y. Hosokawa, M. Yashiro, T. Asahi, H. Fukumura and H. Masuhara, Appl. Surf. Sci., 2000, 154-155, 192-195.

28 G. Compagnini, A. A. Scalisi and O. Puglisi, Phys. Chem. Chem. Phys., 2002, 4, 2787-2791.

29 G. Compagnini, A. A. Scalisi and O. Puglisi, J. Appl. Phys., 2003, 94, 7874-7877.

30 K. Saitow, J. Phys. Chem. B, 2005, 109, 3731-3733.

31 V. Švrček, T. Sasaki, Y. Shimizu and N. Koshizaki, Appl. Phys. Lett., 2006, 89, 213113.

32 (a) I. Umezu, A. Sugimura, M. Inada, T. Makino, K. Matsumoto and M. Takata, Phys. Rev. B: Condens. Matter Mater. Phys., 2007, 76, 045328; (b) I. Umezu, H. Minami, H. Senoo and A. Sugimura, J. Phys.: Conf. Ser., 2007, 59, 392-395.

33 N. Shirahata, M. R. Linford, S. Furumi, L. Pei, Y. Sakka, R. J. Gates and M. C. Asplund, Chem. Commun., 2009, 4684-4686.

34 S. Yang, W. Cai, H. Zhang, X. Xu and H. Zeng, J. Phys. Chem. C, 2009, 113, 19091-19095.

35 K. Saitow and T. Yamamura, J. Phys. Chem. C, 2009, 113, 8465-8470.

36 Y. Kuwahara, T. Saito, M. Haba, T. Iwanaga, M. Sasaki and M. Goto, Jpn. J. Appl. Phys., 2009, 48, 040207.

37 H. Wang, A. Pyatenko, K. Kawaguchi, X. Li, Z. SwiatkowskaWarkocka and N. Koshizaki, Angew. Chem., Int. Ed., 2010, 49, 6361-6364.

38 V. Švrček, D. Mariotti, T. Nagai, Y. Shibata, I. Turkevych and M. Kondo, J. Phys. Chem. C, 2011, 115, 5084-5093.

39 D. Tan, Z. Ma, B. Xu, Y. Dai, G. Ma, M. He, Z. Jin and J. Qiu, Phys. Chem. Chem. Phys., 2011, 13, 20255-20261.

40 C.-C. Huang, K.-Y. Chuang, C.-J. Huang, T.-M. Liu and C.-S. Yeh, J. Phys. Chem. C, 2011, 115, 9952-9960.
41 (a) S. Nakahara, S. Stauss, T. Kato, T. Sasaki and K. Terashima, J. Appl. Phys., 2011, 109, 123304; (b) S. Stauss and K. Terashima, Diamondoids: Synthesis, Properties, and Applications, Pan Stanford, Singapore, 2017.

42 (a) K. Saitow, Y. Okamoto and Y. F. Yano, J. Phys. Chem. C, 2012, 116, 17252-17258; (b) S. Wei, T. Yamamura, D. Kajiya and K. Saitow, J. Phys. Chem. C, 2012, 116, 39283934; (c) K. Saitow, in Laser Ablation in Liquids: Principles and Applications in the Preparation of Nanomaterials, ed. G. W. Yang, Pan Stanford, Singapore, 2012, ch. 12, vol. 573. 43 S. Barcikowski and G. Compagnini, Phys. Chem. Chem. Phys., 2013, 15, 3022-3026.

44 T. Kitasako and K. Saitow, Appl. Phys. Lett., 2013, 103, 151912.

45 (a) A. Pyatenko, H. Wang, N. Koshizaki and T. Tsuji, Laser Photonics Rev., 2013, 7, 596-604; (b) S. Sakaki, H. Ikenoue, T. Tsuji, Y. Ishikawa and N. Koshizaki, ChemPhysChem, 2017, 18, 1101-1107.

46 Y. Xin, K. Nishio and K. Saitow, Appl. Phys. Lett., 2015, 106, 201102.

47 D. Kajiya and K. Saitow, Nanoscale, 2015, 7, 15780-15788.

48 D. Zhang, B. Gökce, C. Notthoff and S. Barcikowski, Sci. Rep., 2015, 5, 13661.

49 S. Scaramuzza, M. Zerbetto and V. Amendola, J. Phys. Chem. $C, 2016,120,9453-9463$.

50 V. Svrcek, D. Mariotti, U. Cvelbar, G. Filipič, M. Lozac'h, C. McDonald, T. Tayagaki and K. Matsubara, J. Phys. Chem. C, 2016, 120, 18822-18830.

51 M. Rodio, R. Brescia, A. Diaspro and R. Intartaglia, J. Colloid Interface Sci., 2016, 465, 242-248.

52 S. Dewan, J. H. Odhner, K. M. Tibbetts, S. Afsari, R. J. Levis and E. Borguet, J. Mater. Chem. C, 2016, 4, 6894-6899.

53 D. Zhang and B. Gökce, Appl. Surf. Sci., 2017, 392, 991-1003. 54 Y. Xin, K. Nishio, M. Maeda and K. Saitow, Chem. Phys. Lett., 2017, 674, 90-97.

55 (a) Z. Yuan, T. Nakamura, S. Adachi and K. Matsuishi, Nanoscale, 2017, 9, 1193-1200; (b) Z. Yuan, T. Nakamura, S. Adachi and K. Matsuishi, J. Phys. Chem. C, 2017, 121, 8623-8629.

56 (a) D. Zhang, B. Gökce and S. Barcikowski, Chem. Rev., 2017, 117, 3990-4103; (b) D. Zhang, W. Choi, K. Yazawa, K. Numata, A. Tateishi, S.-H. Cho, H.-P. Lin, Y. K. Li, Y. Ito and K. Sugioka, ACS Omega, 2018, 3, 10953-10966.

57 Special Issue on Colloids with Lasers, edited by B. Gökce, V. Amendola and S. Barcikowski, ChemPhysChem, 2017, 18, 353, 980-1216.

58 (a) Y. Ishiakwa and N. Koshizaki, Sci. Rep., 2018, 8, 14208; (b) C. L. Sajti, R. Sattari, B. N. Chichkov and S. Barcikowski, J. Phys. Chem. C, 2010, 114, 2421-2427.

59 K. Dohnalová, T. Gregorkiewicz and K. Kůsová, J. Phys.: Condens. Matter, 2014, 26, 173201.

60 X. Li, Y. He and M. T. Swihart, Langmuir, 2004, 20, 47204727.

61 K. Herynková, M. Šlechta, P. Šimáková, A. Fučíková and O. Cibulka, Nanoscale Res. Lett., 2016, 11, 367.

62 Y. Kanemitsu, S. Okamoto, M. Otobe and S. Oda, Phys. Rev. B: Condens. Matter Mater. Phys., 1997, 55, R7375-R7378. 
63 C. Y. Liu, Z. C. Holman and U. R. Kortshagen, Nano Lett., 2009, 9, 449-452.

64 (a) F. Hua, M. T. Swihart and E. Ruckenstein, Langmuir, 2005, 21, 6054-6062; (b) Y. He, Z.-H. Kang, Q.-S. Li, C. H. A. Tsang, C.-H. Fan and S.-T. Lee, Angew. Chem., Int. Ed., 2009, 48, 128-132; (c) F. Erogbogbo, K. T. Yong, I. Roy, G. Xu, P. N. Prasad and M. T. Swihart, ACS Nano, 2008, 2, 873-878.

65 (a) C. M. Gonzalez and J. G. C. Veinot, J. Mater. Chem. C, 2016, 4, 4836-4846; (b) M. Segev-Bar and H. Haick, ACS Nano, 2013, 7, 8366-8378; (c) S. Kano, K. Kim and M. Fujii, ACS Sens., 2017, 2, 828-833.

66 (a) K. H. Kim, D. J. Lee, K. M. Cho, S. J. Kim, J.-K. Park and H.-T. Jung, Sci. Rep., 2015, 5, 9014; (b) Z. Chen, C. Wang, J. Lopez, Z. Lu, Y. Cui and Z. Bao, Adv. Energy Mater., 2015, 1401826; (c) X. Zuo, Y. Xia, Q. Ji, X. Gao, S. Yin, M. Wang, X. Wang, B. Qiu, A. Wei, Z. Sun, Z. Liu, J. Zhu and Y.-J. Cheng, ACS Nano, 2017, 11, 889-899; (d) Z. Liu, X. Chang, T. Wang, W. Li, H. Ju, X. Zheng, X. Wu, C. Wang, J. Zheng and X. Li, ACS Nano, 2017, 11, 6065-6073.

67 H. Sugimoto, K. Furuta and M. Fujii, J. Phys. Chem. C, 2016, 120, 24469-24475.

68 L. M. Wheeler, N. R. Neale, T. Chen and U. R. Kortshagen, Nat. Commun., 2013, 4, 2197.

69 X. Cheng, S. B. Lowe, P. J. Reece and J. J. Gooding, Chem. Soc. Rev., 2014, 43, 2680-2700.

70 L. A. Huck and J. M. Buriak, J. Am. Chem. Soc., 2012, 134, 489-497.

71 F. Priolo, T. Gregorkiewicz, M. Galli and T. F. Krauss, Nat. Nanotechnol., 2014, 9, 19-32.

72 F. P. McVey and R. D. Tilley, Acc. Chem. Res., 2014, 47, 30453051.

73 F. Peng, Y. Su, Y. Zhong, C. Fan, S.-T. Lee and Y. He, Acc. Chem. Res., 2014, 47, 612-623.

74 V. Svrcek, T. Yamanari, D. Mariotti, S. Mitra, T. Velusamy and K. Matsubara, Nanoscale, 2015, 7, 11566-11574.

75 (a) W. Sun, C. Qian, L. He, K. K. Ghuman, A. P. Y. Wong, J. Jia, A. A. Jelle, P. G. O'Brien, L. M. Reyes, T. E. Wood, A. S. Helmy, C. A. Mims, C. V. Singh and G. A. Ozin, Nat. Commun., 2016, 7, 12553; (b) F. Erogbogbo, T. Lin, P. M. Tucciarone, K. M. LaJoie, L. Lai, G. D. Patki, P. N. Prasad and M. T. Swihart, Nano Lett., 2013, 13, 451-456.

76 (a) T. M. Atkins, M. C. Cassidy, M. Lee, S. Ganguly, C. M. Marcus and S. M. Kauzlarich, ACS Nano, 2013, 7, 2676-2685; (b) C. Tu, X. Ma, A. House, S. M. Kauzlarich and A. Y. Louie, ACS Med. Chem. Lett., 2011, 2, 285-288.

77 H. Sun, S. Miyazaki, H. Tamamitsu and K. Saitow, Chem. Commun., 2013, 49, 10302-10304.

78 D. Kajiya, T. Koganezawa and K. Saitow, AIP Adv., 2015, 5, 127130.
79 G. Viera, S. Huet and L. Boufendi, J. Appl. Phys., 2001, 90, 4175.

80 C. M. Hessel, J. Wei, D. Reid, H. Fujii, M. C. Downer and B. A. Korgel, J. Phys. Chem. Lett., 2012, 3, 1089-1093.

81 P. Yogi, M. Tanwar, S. K. Saxena, S. Mishra, D. K. Pathak, A. Chaudhary, P. R. Sagdeo and R. Kumar, Anal. Chem., 2018, 90, 8123-8129.

82 Y. Lin, T. Y. Tsui and J. J. Vlassak, J. Electrochem. Soc., 2006, 153, F144-F152.

83 M. Künle, T. Kaltenbach, P. Löper, A. Hartel, S. Janz, O. Eibl and K.-G. Nickel, Thin Solid Films, 2010, 519, 151-157.

84 J.-M. Philippoz, R. Zenobi and R. N. Zare, Chem. Phys. Lett., 1989, 158, 12-17.

85 (a) Heat conduction to bulk-Si wafer is treated in eqn (2) and (3) that does not involve solvent parameter due to 1000 times higher thermal conductivity of Si $\left(150 \mathrm{~W} \mathrm{~m}^{-1} \mathrm{~K}^{-1}\right)$ than IPA $\left(0.16 \mathrm{~W} \mathrm{~m}^{-1} \mathrm{~K}^{-1}\right) .{ }^{86}$ For the cooling of hot nano and submicrometer particles, the heat dissipation to solvent has been discussed..$^{45}$; $(b)$ In the case of PLAL, materials detached by ablation are dispersed in liquid after undergoing complex dynamic processes such as plasma plumes, cavitation bubbles, nuclei growth, and particle formation. ${ }^{\mathbf{2 4 5 6}}$ In the particle size of final product, it is quickly cooled in the liquid (Note $\mathrm{S} 4 \dagger$ ).

86 CRC Handbook of Chemistry and Physics, ed. W. M. Haynes, CRC Press, Boca Raton, FL, 2014.

87 A. X. Wang, Y. H. Yang, N. S. Xu and G. W. Yang, J. Am. Chem. Soc., 2004, 126, 11303-11306.

88 B. H. Bui, R. S. Zhu and M. C. Lin, J. Chem. Phys., 2002, 117, 11188-11195.

89 S. Savagatrup, A. D. Printz, T. F. O'Connor, A. V. Zaretski, D. Rodriquez, E. J. Sawyer, K. M. Rajan, R. I. Acosta, S. E. Root and D. J. Lipomi, Energy Environ. Sci., 2015, 8, 55-80.

90 D. Kajiya, T. Koganezawa and K. Saitow, J. Phys. Chem. C, 2016, 120, 23351-23357.

91 F. Zhang, B. Sun, T. Song, X. Zhu and S. Lee, Chem. Mater., 2011, 23, 2084-2090.

92 L. He, C. Jiang, H. Wang, D. Lai and Rusli, Appl. Phys. Lett., 2012, 100, 073503.

93 M. Al-Ibrahim, H.-K. Roth, M. Schroedner, A. Konkin, U. Zhokhavets, G. Gobsch, P. Scharff and S. Sensfuss, Org. Electron., 2005, 6, 65-77.

94 P. C. Hiemenz, Principles of colloid and surface chemistry, CRC Press, New York, 1986.

95 L. Bergström, Adv. Colloid Interface Sci., 1997, 70, 125-169.

96 M. Matsumoto, A. G. Gaonkar and T. Takenaka, Bull. Inst. Chem. Res., Kyoto Univ., 1980, 58, 523-533.

97 R. J. Hunter, Foundations of colloid science, Clarendon Press, Oxford, 1987.

98 J. Visser, Adv. Colloid Interface Sci., 1972, 3, 331-363. 